\title{
Equatorial Waves in a General Circulation Model
}

\section{Simulating a Quasi-Biennial-Oscillation}

\author{
By Masaaki Takahashi, Nan Zhao \\ Center for Climate System Research, University of Tokyo, Tokyo 153, Japan \\ and \\ Toshiro Kumakura \\ Department of Civil and Environmental Engineering, Nagaoka University of Technology, \\ Nagaoka 940-21, Japan \\ (Manuscript received 10 May 1996, in revised form 27 December 1996)
}

\begin{abstract}
The quasi-biennial oscillation (QBO) in the equatorial lower stratosphere has been well simulated in the first version of the Center for Climate System Research / National Institute for Environmental Studies (CCSR/NIES) atmospheric general circulation model (Takahashi, 1996). The model horizontal resolution is T21 with 60 layers of vertical resolution of about $500 \mathrm{~m}$ in the upper troposphere and lower stratosphere, with a moist convective adjustment scheme. The period of the simulated oscillation is 1.5 years, which is slightly shorter than that observed.

The equatorial wave behavior in the model is examined using the spectral analysis method. The westerly acceleration phase of the QBO-like oscillation in the model is due to Kelvin waves and eastwardpropagating gravity waves. The easterly acceleration phase of the oscillation is due to westward-propagating $n=1$ equatorial gravity waves, random westward-propagating gravity waves and Rossby waves propagating from the mid-latitudes in the northern winter hemisphere to the equatorial region. The Rossby-gravity wave has a role in the easterly acceleration of the QBO-like oscillation in the present general circulation model.
\end{abstract}

\section{Introduction}

The quasi-biennial oscillation (QBO) in the equatorial lower stratosphere is an interesting phenomenon, which is explained by Holton and Lindzen (1972) using a wave mean-flow interaction theory. In their theory, the Kelvin and Rossby-gravity waves, which propagate from the tropical troposphere into the lower stratosphere and are dissipated by Newtonian cooling, produce the westerly and easterly phases of the QBO, respectively. Yanai and Maruyama (1966) discovered Rossby-gravity waves of zonal wave number 4 and a period of about 4.5 days. Wallace and Kousky(1968) found Kelvin waves of zonal wavenumber 1 or 2 and a period of about 15 days.

Recently, Maruyama (1994) found a short period eastward-propagating wave of which the wave momentum flux is comparable to that of the so-called

(C)1997, Meteorological Society of Japan
Wallace-Kousky wave (see also Sato et al., 1994). The observations suggest that the Wallace-Kousky wave is not alone in making a contribution to the westerly acceleration phase, but is aided by shortperiod Kelvin, inertia-gravity, and gravity waves.

On the other hand, the deficiency in the easterly momentum flux of the Rossby-gravity wave has already been mentioned by Lindzen and Tsay (1975). They suggested that another candidate is the meridional mode number $n=1$ equatorial gravity wave which was not resolved in their analysis (see also Takahashi and Holton (1991) for a mechanistic model study). Recently, Takayabu (1994a, b) found $n=1$ westward-propagating equatorial gravity wave signals in the satellite cloud data. The $n=1$ equatorial gravity wave has about 2-day period. However, the $n=1$ equatorial gravity wave behavior is not very clear in the stratosphere ( $c f$. Maruyama, 1994; Sato et al., 1994).

Concerning general circulation model (GCM) 
studies, Hayashi and Golder (1994) demonstrated that the realistic N30 GFDL SKYHI general circulation model adequately produces both Kelvin and Rossby-gravity waves. They also suggested that the weakness of the QBO simulated in the model is due to small-scale gravity waves not being adequately produced.

Recently, a QBO-like oscillation in a threedimensional mechanistic model has been obtained. The horizontal resolution is the same as T106, however, the model resolves $1 / 5$ sector only in the zonal direction and has an aqua-planet condition on the surface(Takahashi and Shiobara, 1995; Takahashi and Kumakura, 1995). The downward-propagating structure and amplitude of the oscillation are similar to that of the observed QBO. However, the period of the oscillation is about 400 days, half as long as that of the observed $\mathrm{QBO}$ in the equatorial lower stratosphere. Further, the height of the simulated oscillation is about $15 \mathrm{~km}$ higher than that of the observed QBO. In the model, $n=1$ westwardpropagating equatorial gravity waves and random eastward-propagating gravity waves are responsible for the production of the QBO-like oscillation.

More recently, the QBO has been fairly well simulated by use of a T21 60-layer (T21L60) general circulation model with moist convective adjustment scheme(Takahashi, 1996). The damping time for the maximum wavenumber in the fourth-order horizontal diffusion was 20 days. The 20-day damping time is about one-order of magnitude less than that used in standard general circulation models ( $c f$. Boville, 1991). The period of the simulated oscillation is 1.5 years, which is slightly shorter than that observed, and the height of the oscillation is slightly higher than that observed. On the other hand, an idealized T21L60 mechanistic model with an aqua-planet surface, no annual cycle and no mountains has about a 4-year QBO-like oscillation, as will be shown below.

In the present paper, equatorial wave behavior in the model is presented. The model used in the present work is briefly mentioned in Section 2. In Section 3, numerical results and spectral analysis of equatorial waves contributing to the QBO-like oscillation are presented. Finally, concluding remarks are given in Section 4.

\section{Model}

The model is the first version of the atmospheric general circulation model which was developed at the Center for Climate System Research / National Institute for Environmental Studies (CCSR/NIES). The basic features of the model can be found in a paper by Numaguti (1993). Newly implemented physical processes are discussed in Numaguti et al. (1995). A detailed description of the radiation scheme can be found in Nakajima et al. (1995).
The horizontal resolution is $\mathrm{T} 21$, which corresponds to a grid spacing of about $600 \mathrm{~km}$. There are 60 layers in the vertical, having about $500 \mathrm{~m}$ vertical resolution in the upper troposphere and lower stratosphere. The top level of the model is located at about $0.5 \mathrm{mb}$ (approximately $50 \mathrm{~km}$, the 0.0005 sigma level).

Following previous experiments (Takahashi and Shiobara, 1995; Takahashi and Kumakura, 1995), the moist convective adjustment scheme is also used as the cumulus parameterization in this experiment, although the standard convection scheme of the CCSR/NIES GCM is the prognostic ArakawaSchubert scheme (Numaguti et al., 1995). The magnitude of the minimum vertical eddy viscosity coefficient is set to $0.1 \mathrm{~m}^{2} \mathrm{~s}^{-1}$, even though the MellorYamada level-2 closure scheme is used as the vertical eddy viscosity in the free atmosphere, as well as in the bottom boundary layer.

As mentioned in the Introduction, the damping time for the maximum wavenumber in the fourthorder horizontal diffusion is 20 days, being about one-order of magnitude less than that usually used in general circulation models. This small value of the horizontal diffusion is a necessary characteristic of the present GCM experiment of the QBO, as well as high vertical resolution. It is noted that there is no oscillation in the case of 4-day damping time (see Takahashi, 1996). The effects of orographically excited subgrid-scale internal gravity waves are included through McFarlane's parameterization (1987). The dry convective adjustment scheme is also applied in the stratosphere to represent wave breaking. The other processes and schemes are the same as those in the standard GCM experiments. For example, use is made of a climatological seasurface temperature distribution and realistic mountains, among others.

The initial condition is an isothermal atmosphere at rest. The first day of the simulation is the 1st of January of the zeroth year (day $=0)$, and 360 days constitutes one year. A strong Rayleigh damping (1day damping time) near the top boundary is used during the first three months of the simulation. After three months, a smaller value (10 days near the top boundary) of Rayleigh friction is used.

\section{Results}

\subsection{A QBO-like oscillation and net wave activity over the equator}

Figure 1 shows the time-height section of the simulated mean zonal wind over the equator. A QBOlike oscillation in the equatorial middle stratosphere (about $15 \mathrm{mb}$ ) can be clearly seen in Fig. 1. The amplitude of the zonal-wind of the oscillation is about $20 \mathrm{~ms}^{-1}$ (maximum westerlies of about $20 \mathrm{~ms}^{-1}$; maximum easterlies of about $-15 \mathrm{~ms}^{-1}$ ). The westerly phase of the oscillation is, however, stronger 


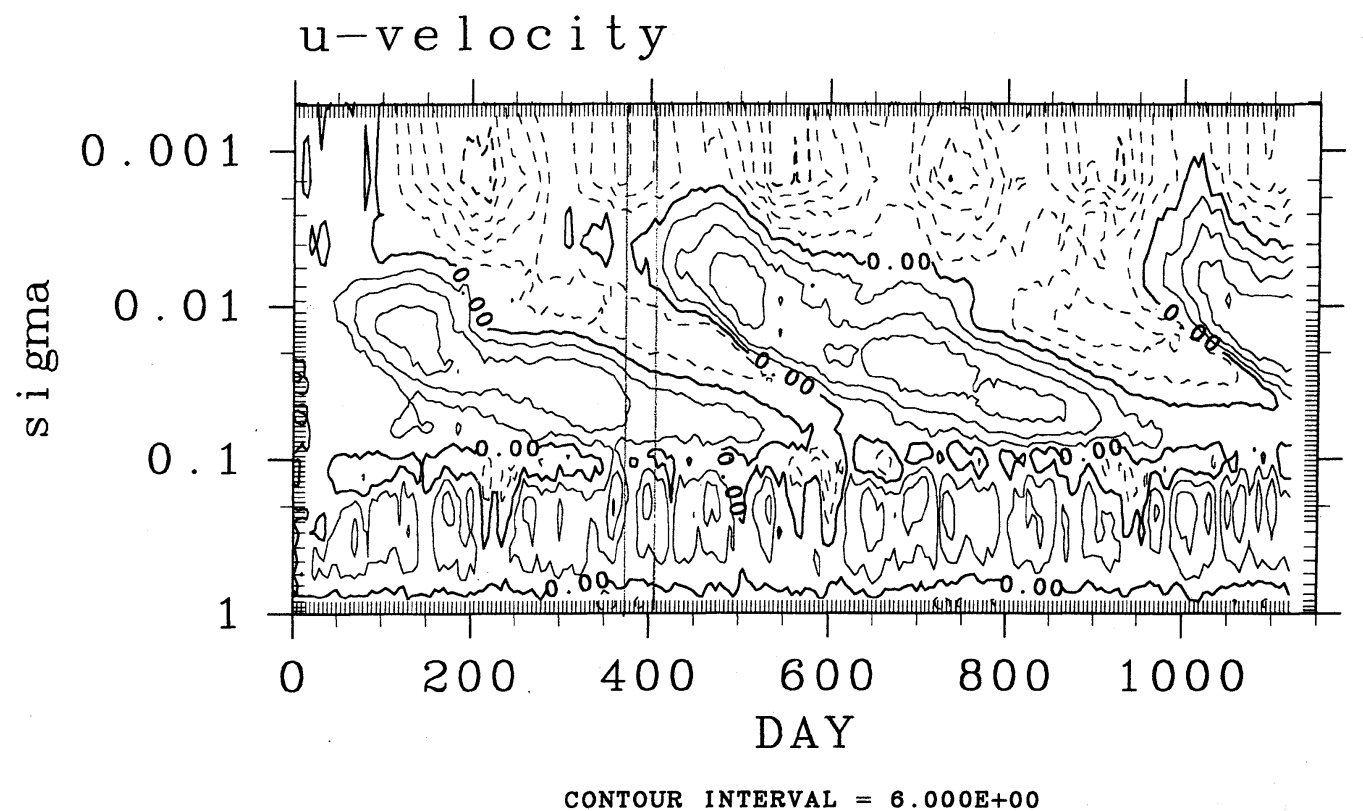

Fig. 1. Time-height section of the simulated mean zonal wind over the equator. The time coordinate is from day 0 ( $1 \mathrm{Jan}$. 0 -th year) to day 1122.5. The contour interval is $6 \mathrm{~ms}^{-1}$. The solid lines represent westerlies and the dashed lines easterlies. The vertical lines in the figure indicate the wave analysis time of days $375-405$.

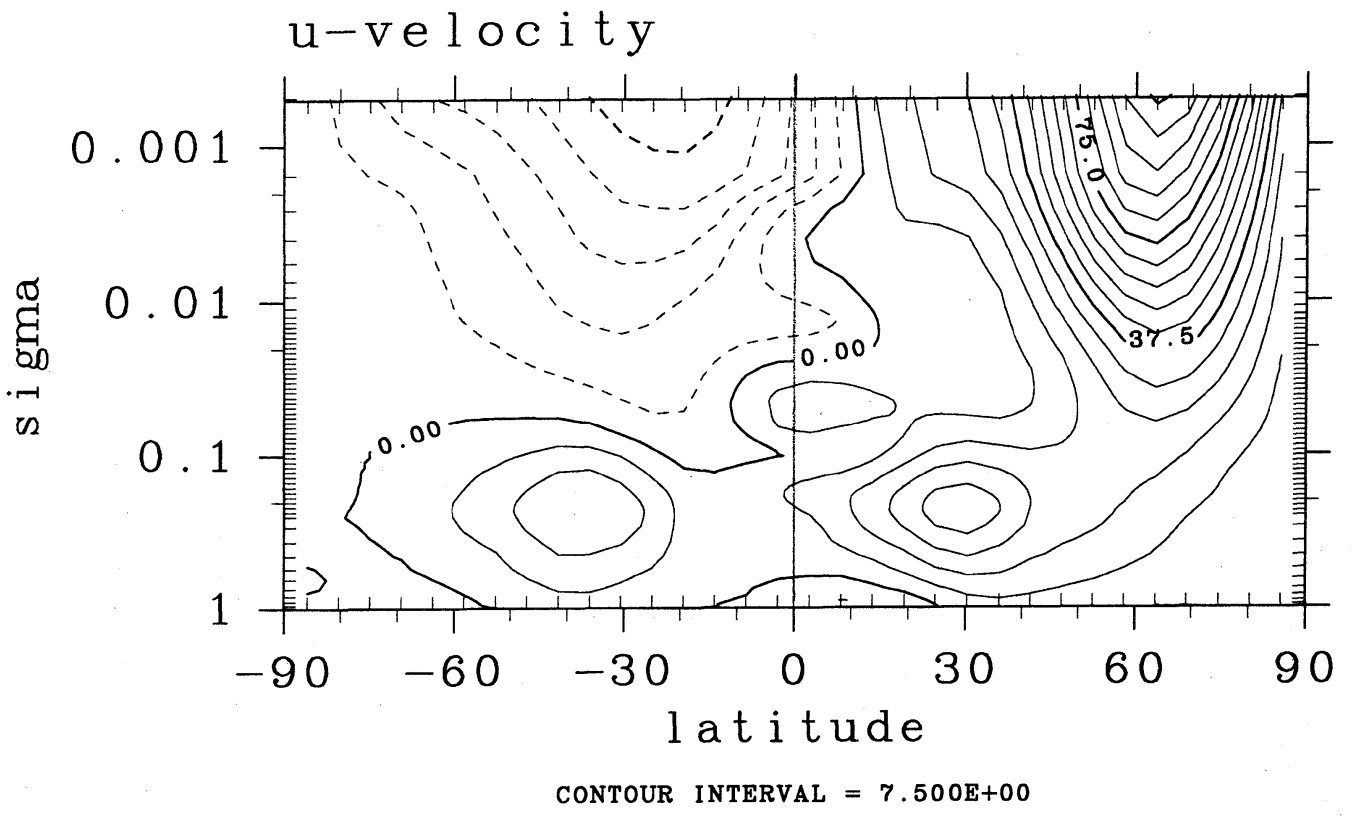

Fig. 2. Latitude-height section of the time-averaged mean zonal wind for days 375-405 (16 Jan. first year-16 February). The contour interval is $7.5 \mathrm{~ms}^{-1}$. The solid lines are westerlies; dashed lines are easterlies.

than the easterly phase in the model simulation. This is the reverse of that observed (see Naujokat, 1986: the maximum easterlies are about $-30 \mathrm{~ms}^{-1}$; the maximum westerlies $15 \mathrm{~ms}^{-1}$ ). The height of the oscillation is slightly higher than that of the QBO. Mainly the easterly phase is too high. This is related to the general weakness of the easterly phase. The period of the simulated oscillation is 1.5 years, being slightly shorter than that of the observed QBO. The simulated oscillation, in other respects, resembles the QBO very well.

Figure 2 shows the latitude-height section of mean zonal wind time-averaged over days 375-405 (northern hemisphere winter from Jan. 16 of the first year 


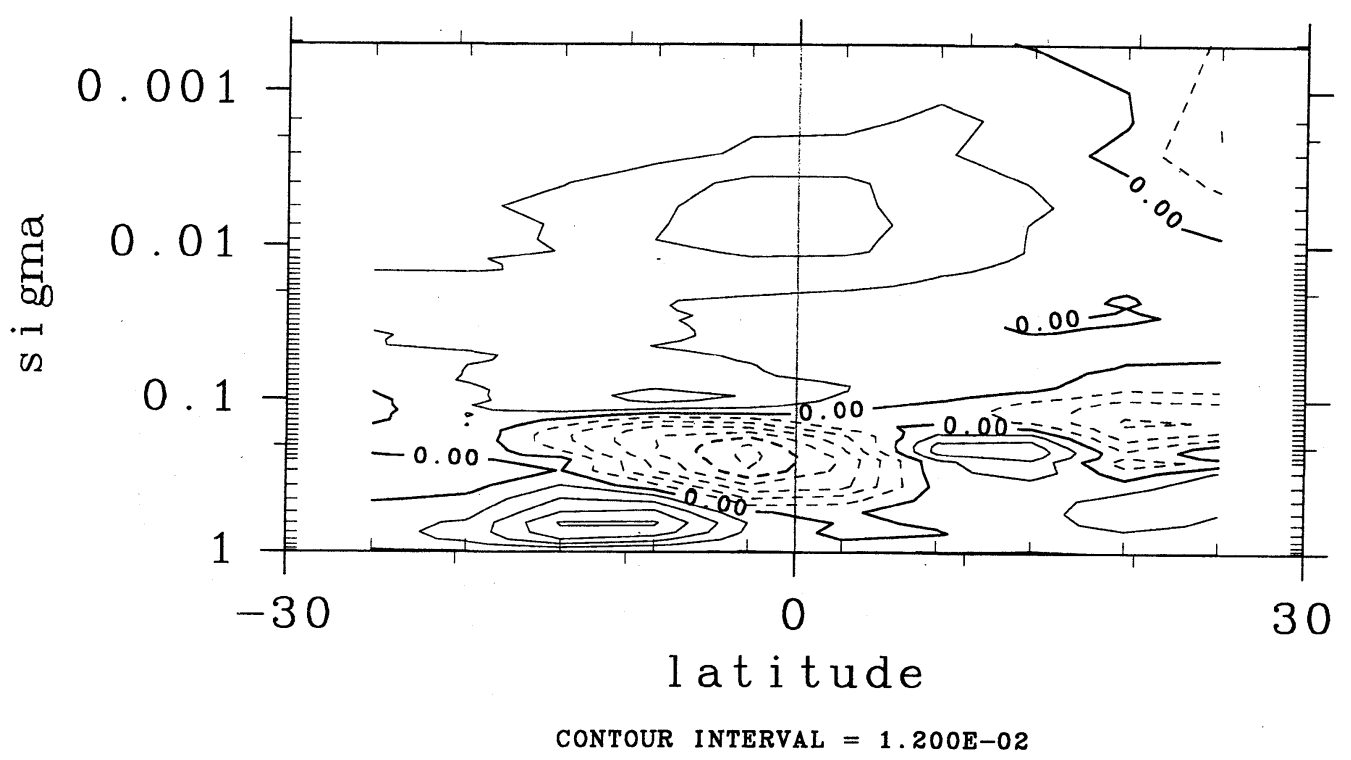

Fig. 3. Latitude-height section of the time-averaged vertical wave momentum flux $\overline{u^{\prime} w^{\prime}}$ from days 375 to 405. The contour interval is $1.2 \times 10^{-2} \mathrm{~m}^{2} \mathrm{~s}^{-2}$. The solid lines represent westerly upward momentum flux, and the dashed lines easterly upward momentum flux. The easterly acceleration phase of the $\mathrm{QBO}$ is in the middle stratosphere at days $375-405$.

to Feb. 16). The basic structure is similar to that of the observed January-mean zonal wind, even though the westerlies in the winter hemisphere are stronger than that observed. This may be due to the weaker 10-day Rayleigh damping near the top boundary. There are easterlies at sigma $=0.001$ (about the $1 \mathrm{mb}$ level) over the equator. This is the easterly phase of the semiannual oscillation around the stratopause level. But there are no westerlies of the semiannual oscillation at the equinoxes in the model simulation, as shown in Fig. 1. Around the sigma $=0.015$ (about $15 \mathrm{mb}$ ) level over the equator, the easterly phase of the QBO is seen, and there are westerlies of the QBO around the sigma=0.05 (about $50 \mathrm{mb}$ ) level. The meridional extent of the QBO is approximately $1500 \mathrm{~km}$. The value is comparable to that observed ( $c f$. Wallace, 1973). In the next sub-section, a wave analysis is performed in this time period. There are westerlies in the equatorial middle and upper troposphere. This is a defect of the low-resolution CCSR/NIES GCM.

Figure 3 shows a latitude-height section of the time-averaged vertical wave momentum flux $\overline{u^{\prime} w^{\prime}}$ for days 375-405. As noticed from Fig. 1, this time corresponds to the easterly phase of the QBO in the middle stratosphere and westerly phase in the lower stratosphere. The vertical wind $w$ is approximated by the following equation as in our previous paper (Takahashi and Kumakura, 1995):

$$
p\left(\frac{\dot{\sigma}}{\sigma}+\frac{d \ln p_{s}}{d t}\right)=\omega=\frac{d p}{d t} \approx-\frac{p}{H} w
$$

where $H$ is the scale height (a value of $7 \mathrm{~km}$ is as- sumed). There is westerly momentum flux upward in the lower and middle stratosphere, and easterly momentum flux upward in the troposphere over the equator. Note here that the part of the vertical Eliassen-Palm (EP) flux

$$
\frac{\left(2 \Omega \sin \phi-\frac{\partial(\bar{u} \cos \phi)}{a \cos \phi \partial \phi}\right)}{N^{2}} \frac{R}{H} \overline{v^{\prime} T^{\prime}}
$$

(this is an approximate form; see Takahashi and Holton, 1991) is much smaller than $\overline{u^{\prime} w^{\prime}}$ near the equator (not shown). Therefore, the acceleration of the mean zonal wind over the equator can be estimated from the divergence of $\rho \overline{u^{\prime} w^{\prime}}$.

Figures $4 \mathrm{a}$ and $4 \mathrm{~b}$ show the vertical distributions of density weighted momentum flux $\rho \overline{u^{\prime} w^{\prime}}$ and the convergence of momentum flux $-\frac{1}{\rho} \frac{d\left(\rho \overline{u^{\prime} w^{\prime}}\right)}{d z}$ over the equator, respectively. As suggested from Fig. 3 , the westerly momentum flux is positive in the whole stratosphere and negative in the upper troposphere. The convergence of wave momentum flux (the solid line in Fig. 4b) induces westerly acceleration in the upper stratosphere and lower stratosphere. The magnitude is approximately $4 \times$ $10^{-6} \mathrm{~ms}^{-1}$ ( $10 \mathrm{~ms}^{-1} /$ month). The value is rather high but realistic. There is easterly acceleration in the middle stratosphere. The magnitude of easterly acceleration is about $-1 \times 10^{-6} \mathrm{~ms}^{-2}$ in the middle stratosphere. The magnitude is slightly small to produce the QBO-like oscillation at these altitudes. The westerly acceleration is stronger than the easterly acceleration. This produces a stronger westerly than easterly in the oscillation, as mentioned above. 
(a)

\section{Vertical Momentum Flux}

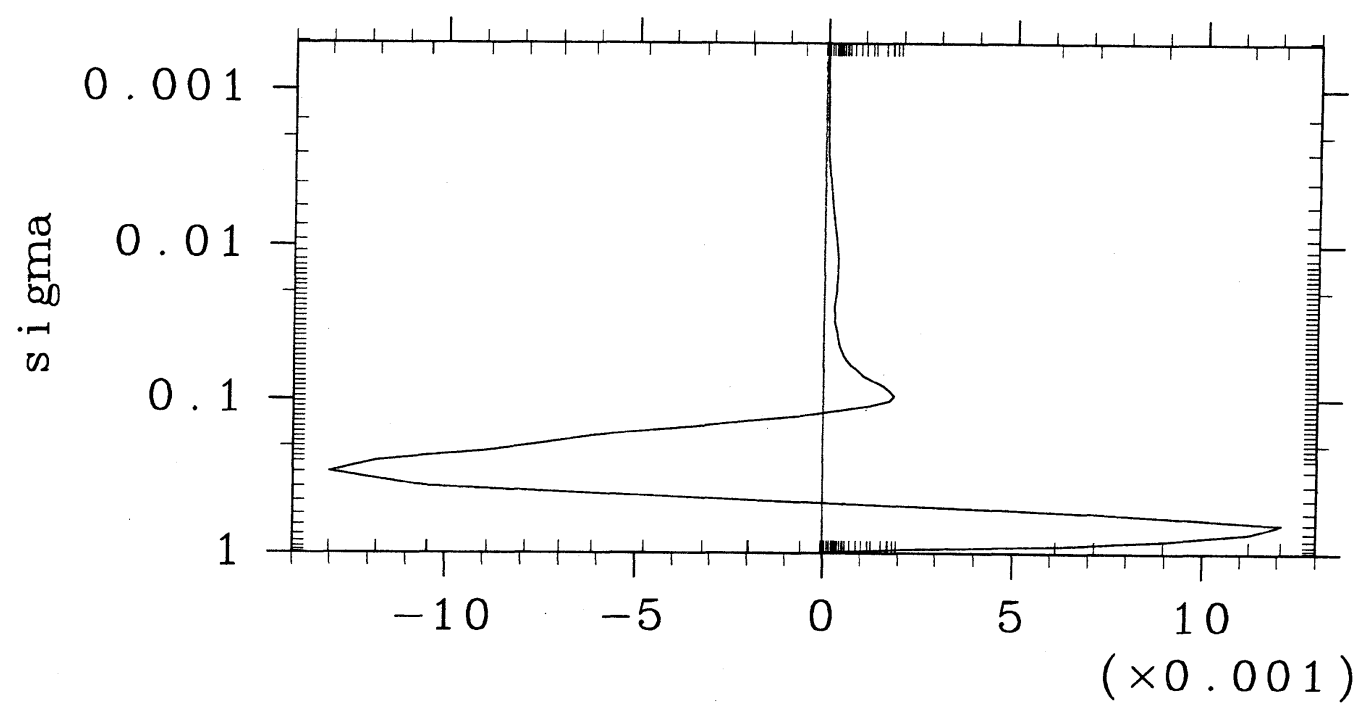

(b)
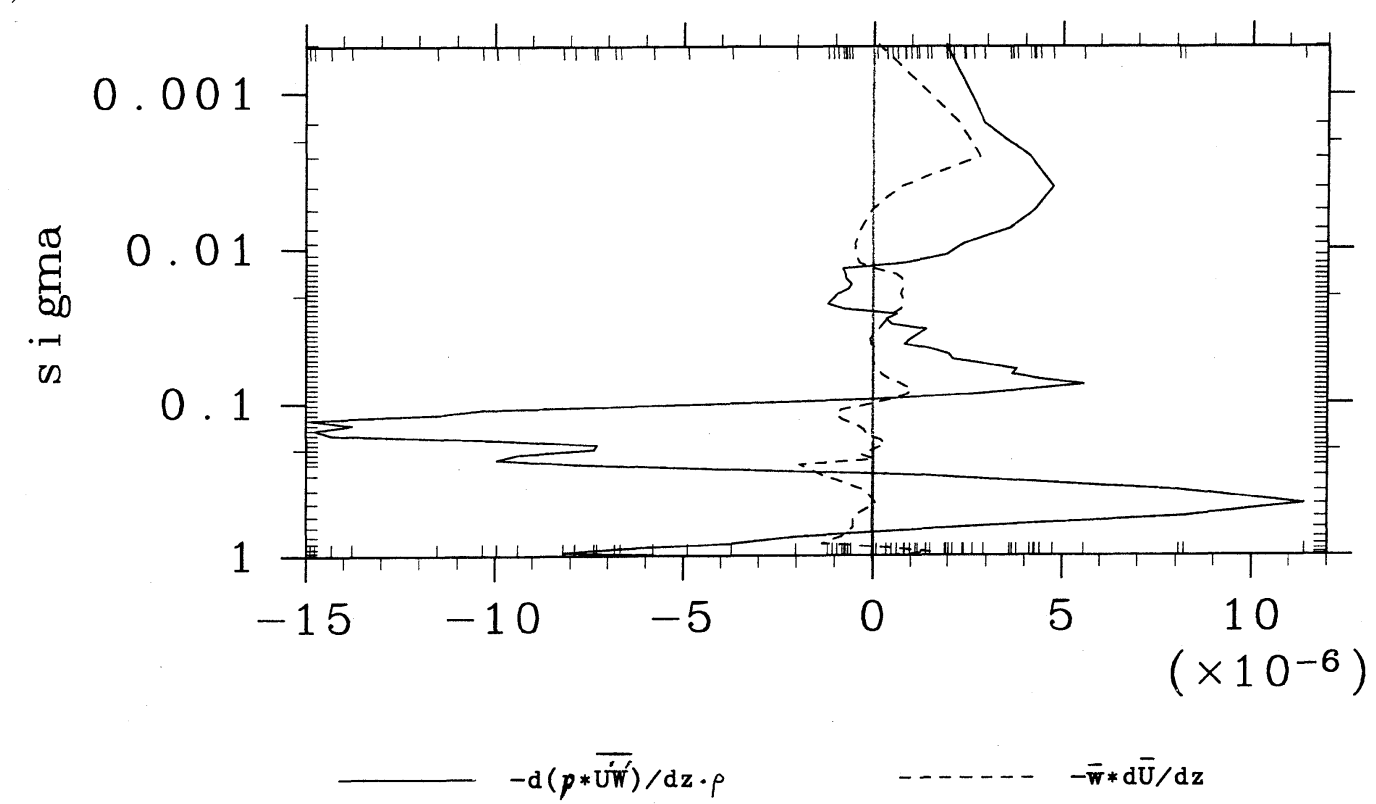

Fig. 4. (a) Vertical distribution of the density-weighted vertical wave momentum flux $\rho \overline{u^{\prime} w^{\prime}}$ meridionally averaged from $-8^{\circ} \mathrm{S}$ to $8^{\circ} \mathrm{N}$. The unit is $10^{-3} \mathrm{~kg} \mathrm{~m}^{-1} \mathrm{~s}^{-2}$. (b) Same as Fig. 4a, except for momentum flux convergence $-\frac{1}{\rho} d\left(\rho \overline{u^{\prime} w^{\prime}}\right) / d z$ (solid line) and non-linear advection term $-\bar{w} \frac{\partial \bar{u}}{\partial z}$ (dashed line). The unit is $10^{-6} \mathrm{~m} \mathrm{~s}^{-2}$.

The non-linear advection term $-\bar{w} \frac{\partial \bar{u}}{\partial z}$ has a rather complicated structure (the dashed line in Fig. 4b). Note, however, that the upwelling term has positive maxima in each of the descending shear zones. Also, the magnitude is relatively less than the wave momentum flux convergence (the maximum amplitude is at most $1 \times 10^{-6} \mathrm{~ms}^{-2}$ in the middle and lower stratosphere, and the vertical scale is small). The vertical advection term could still play a significant role in the present simulation.

Figures $5 \mathrm{a}$ and $5 \mathrm{~b}$ show the meridional momen- tum flux $\overline{u^{\prime} v^{\prime}}$ at days $375-405$ (from Jan. 16 of the first year to Feb. 16) in the northern hemisphere winter and the convergence of momentum flux $-\frac{1}{\cos ^{2} \phi} \frac{\partial}{\partial y}\left(\overline{u^{\prime} v^{\prime}} \cos ^{2} \phi\right)$ vertically averaged from sigma 0.1 to 0.01 , respectively. The magnitude of the easterly acceleration is approximately $-2 \times$ $10^{-6} \mathrm{~ms}^{-2}$ over the equator. The value is almost the same as that estimated by Dunkerton (1983). This value is also larger than the easterly acceleration in the middle stratosphere due to the convergence of vertical wave momentum flux $\rho \overline{u^{\prime} w^{\prime}}$ (see 
(a)

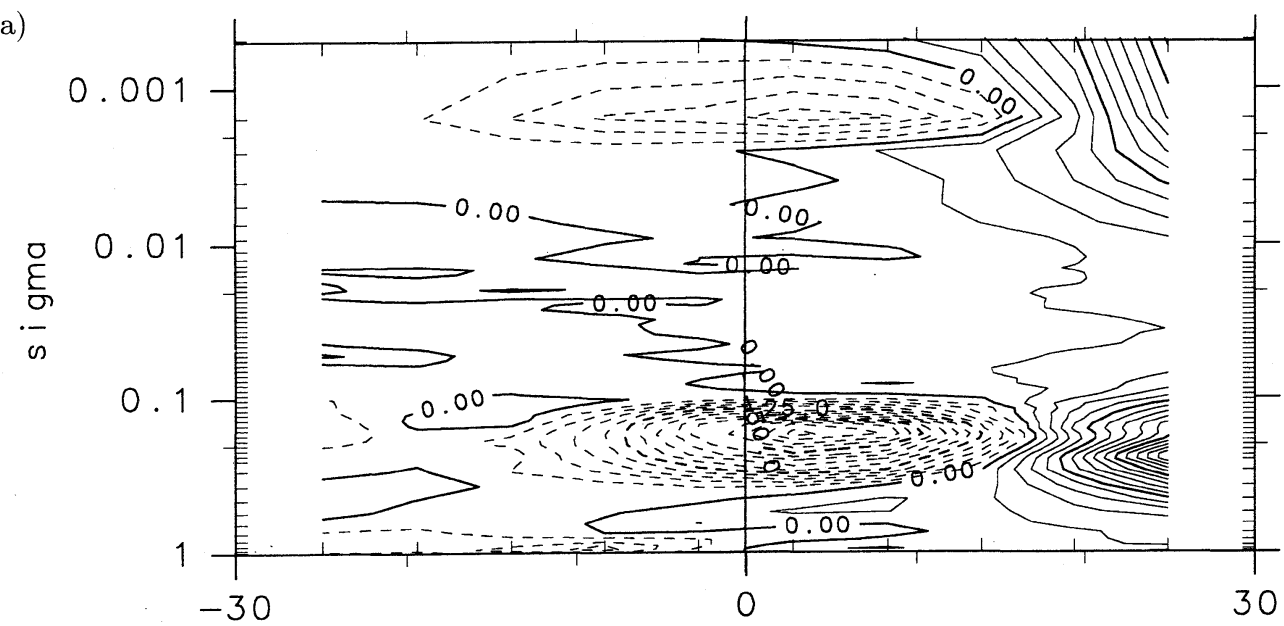

lat i tude

CONTOUR INTERVAL $=5.000 E+00$

(b)

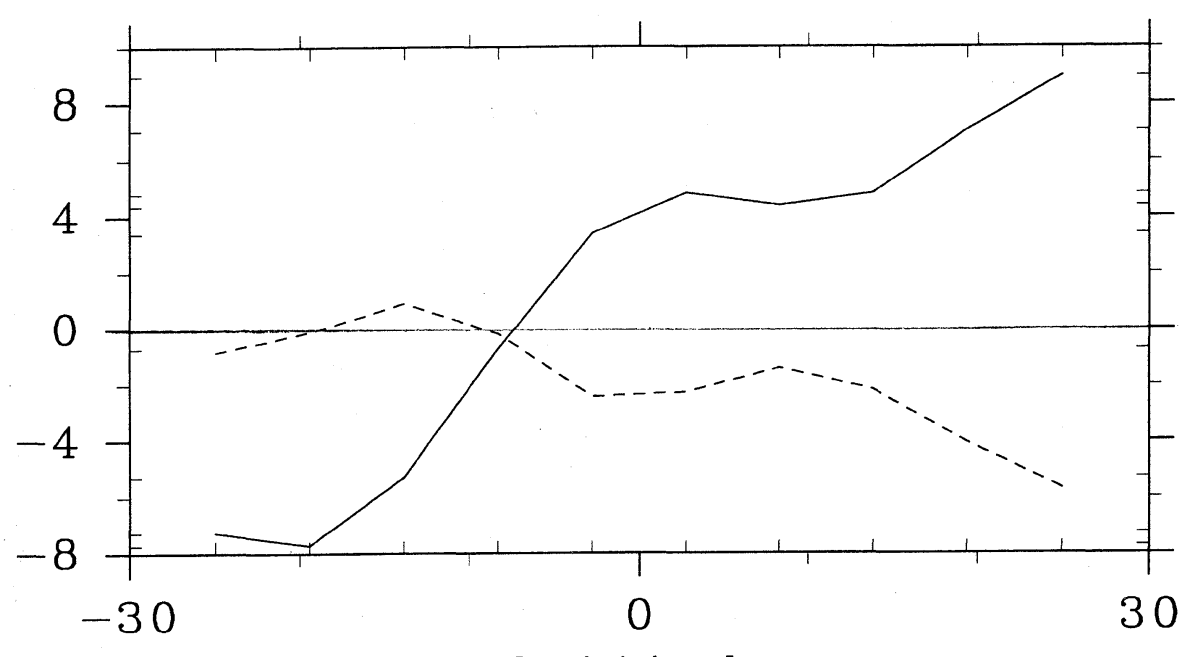

l at itude

Fig. 5. (a) Latitude-height section of the time-averaged horizontal wave momentum flux $\overline{u^{\prime} v^{\prime}}$ from days 375 to 405 . The contour interval is $5 \mathrm{~m}^{2} \mathrm{~s}^{-2}$. There is the southward easterly wave momentum flux from the winter hemisphere in the middle stratosphere. (b) Meridional distribution of mean zonal wind (solid line) and the convergence of horizontal wave momentum flux $-\frac{1}{\cos ^{2} \phi} \frac{\partial}{\partial y}\left(\overline{u^{\prime} v^{\prime}} \cos ^{2} \phi\right)$ (dashed line) vertically averaged from sigma $=0.1$ to 0.01 . The unit is $\mathrm{ms}^{-1}$ for mean zonal wind and $10^{-6} \mathrm{~m} \mathrm{~s}^{-2}$ for the convergence of momentum flux, respectively.

Fig. 4b). The horizontal wave momentum flux from the mid-latitude in the northern winter hemisphere, therefore, has a role to play in the easterly acceleration of the model QBO. In the other seasons, there is a small contribution of the easterly acceleration phase of the equatorial QBO. Low horizontal resolution may allow laterally propagating Rossby waves to influence the QBO more than would be found in a high-resolution experiment. This problem, however, is still open to question.

It is noted here that a mechanistic threedimensional global model, which has the same resolution (T21L60) and the same damping time of fourth-order horizontal diffusion, but without mountains and having no annual cycle, has a QBO-like os- cillation in the middle and lower stratosphere with period about 4 years, as shown in Fig. 6. Note that the easterly phase descent is slower, and that this is largely responsible for the longer QBO period. On the other hand, the period of oscillation in the GCM simulation is 1.5 years, as shown in Fig. 1 , about half of that in the mechanistic model result. A dominant dynamical difference of the two models may be Rossby waves propagating from the mid-latitudes to the equatorial region. The mechanistic 'no-mountains' experiment has much smaller Rossby waves from mid-latitudes due to the absence of topography, and therefore it is orographically excited waves that contribute to the QBO in the GCM experiment. On average, the contri- 


$$
\begin{aligned}
& u-v e l o c i t y \\
& m / s
\end{aligned}
$$

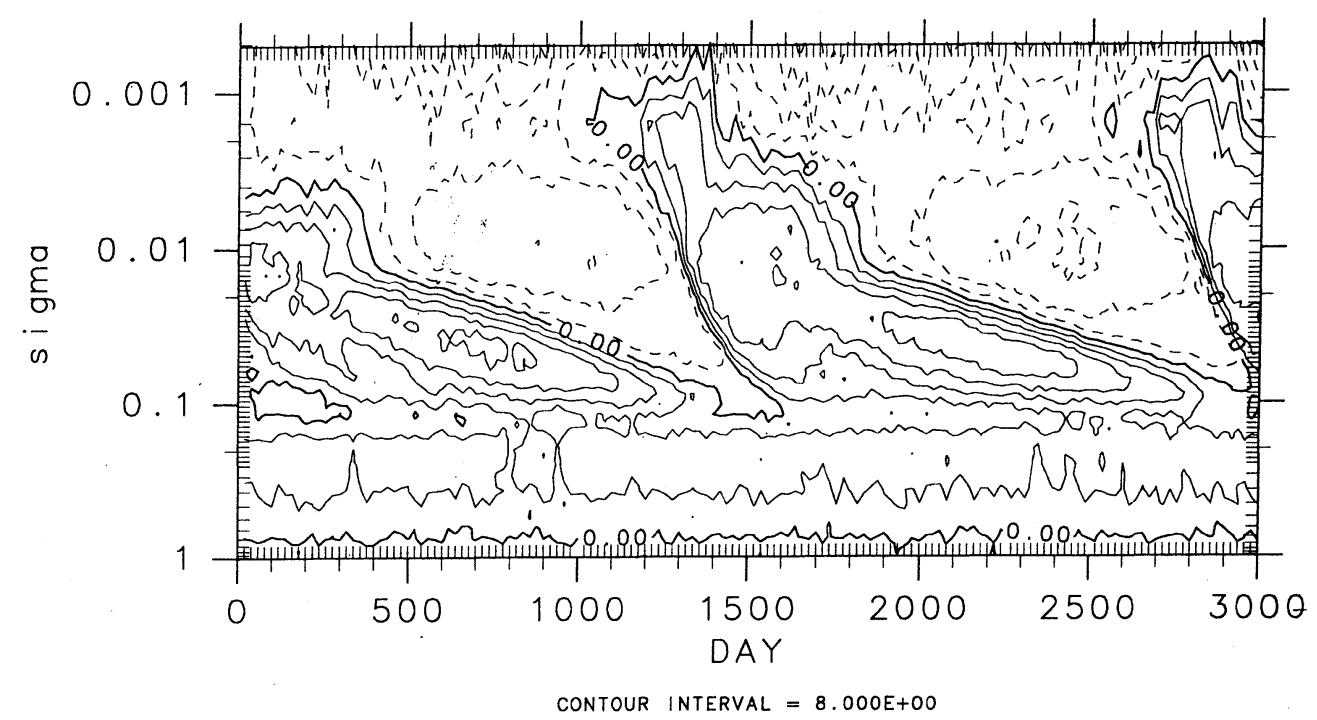

Fig. 6. Time-height section of mean zonal wind over the equator in the case of a T21L60 mechanistic model. The time coordinate is from day 0 to 3000 . The contour interval is $8 \mathrm{~ms}^{-1}$. The solid lines represent westerlies and the dashed lines easterlies.

bution of the easterly acceleration due to Rossby waves from the mid-latitudes is probably about half $\left(-2 \times 10^{-6} \mathrm{~ms}^{-2} / 4\right.$ seasons $\left.\approx-0.5 \times 10^{-6} \mathrm{~ms}^{-2}\right)$ the vertical wave momentum flux.

Conclusively, the dominant contribution to the QBO-like oscillation in the present model is the vertical wave momentum flux convergence $-\frac{1}{\rho} \frac{d\left(\overline{u^{\prime} w^{\prime}}\right)}{d z}$. The magnitude of the easterly flux is smaller than the westerly flux. The meridional momentum flux convergence by Rossby waves from the mid-latitudes into the equatorial region adds to the contribution from the smaller easterly vertically upward momentum flux. The non-linear advection term has a contribution to the acceleration of the QBO-like oscillation.

The spectral analysis of equatorial waves in the model is shown in Subsection 3.2.

\subsection{Wave analysis}

In this subsection, equatorial wave behavior in the general circulation model simulating the QBO-like oscillation is examined. As mentioned above, the wave analyses are performed around days 375-405 of the simulation (the easterly acceleration phase of the QBO-like oscillation in the middle stratosphere and the westerly acceleration phase in the lower stratosphere, as shown in Fig. 1). The calendar time is the northern hemisphere winter from January 16 to February 16 of the first year. The sampling time interval is 6 hours, so the Nyquist time is 12 hours, as in the T106S5 model (see Takahashi and Kumakura, 1995).

\subsubsection{Precipitation}

Figure 7 shows the time-longitude section of precipitation at $3^{\circ} \mathrm{S}$ at days $375-405$. The precipitation is strong around $150^{\circ} \mathrm{E}$ longitude. Similar structures are also around $60^{\circ} \mathrm{E}$ and $60^{\circ} \mathrm{W}$. There is a steady component and moving component. These structures are similar to those in a mechanistic T21L45 model with larger horizontal diffusion by one order, with an aqua-planet surface boundary condition as in the previous paper (Takahashi and Kumakura, 1995). But the precipitation is more confined to localized regions in the present case.

The spectral analysis of the precipitation does not show a clear wavenumber 1 signal. It has a rather scattered wavenumber distribution. The dominant wavenumbers are 1, 3 and 6 (not shown). The dominant signal in frequency is the steady component which is usually seen in the standard GCM simulation ( $c f$. Hayashi and Golder, 1994). From the precipitation it is difficult to see the high-frequency signal corresponding to fast gravity waves.

\subsubsection{Wave signals in the middle stratosphere}

Before the spectral analysis, a time-latitude section of the eddy component of zonal wind at sigma $=0.03$ (about the $30 \mathrm{mb}$ level) at days 375405 is shown in Fig. 8. The position is the zero longitude in the model. Complicated structures are shown, having many time scales from about 10 days to a 1-day period. The meridional structure is also very complicated. It has some modal structures and an asymmetric structure about the equator. 


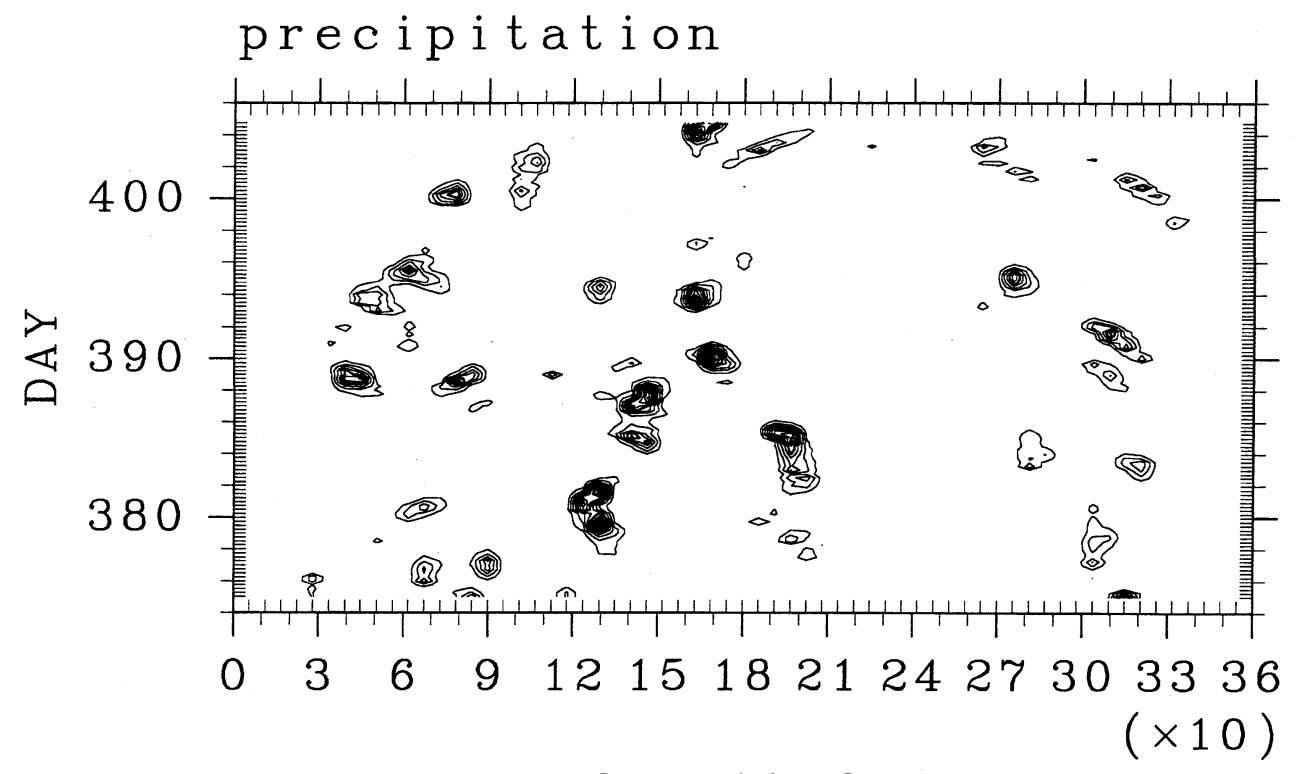

long itude

CONTOUR INTERVAL $=5.000 \mathrm{E}+02$

Fig. 7. Longitude-time section of the precipitation at $3^{\circ} \mathrm{S}$ from days 375 to 405 . The longitude is from 0 to 360 degrees. The contour interval is $500 \mathrm{Wm}^{-2}$ (about $500 \mathrm{~mm} / \mathrm{month}$ ).

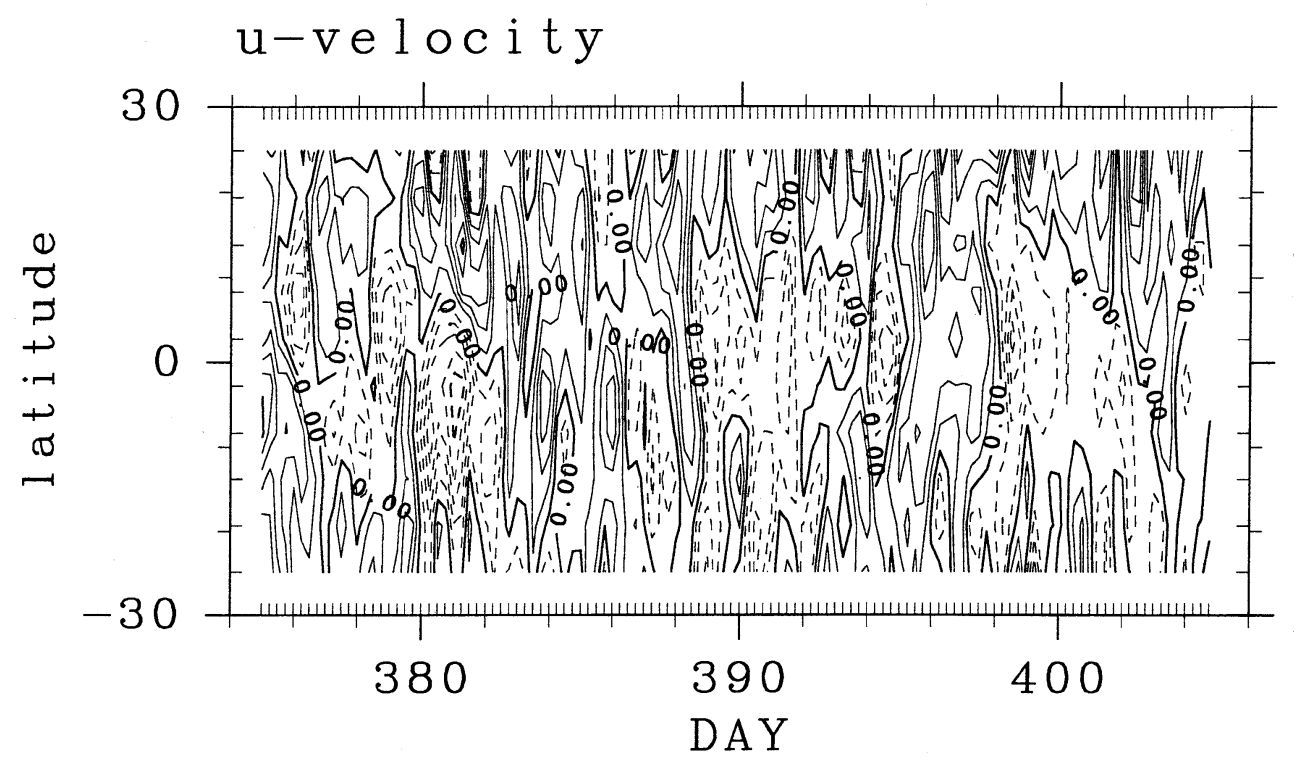

CONTOUR INTERVAL $=4.000 \mathrm{E}+00$

Fig. 8. Time-latitude section of eddy-component of zonal wind from days 375 to 405 at longitude 0 degree. The contour interval is $4 \mathrm{~ms}^{-1}$. The solid lines represent westerlies and the dashed lines easterlies.

1) Westward-propagating waves

Figure 9a shows a frequency-latitude section of the vertical wave momentum flux $\overline{u^{\prime} w^{\prime}}$ at sigma $=0.03$ (about $30 \mathrm{mb}$ level) at days $375-405$. This level corresponds to that of the minimum density-weighted westerly upward wave momentum flux (see Fig. 4a). The zonal wavenumber is integrated from 1 to 5 . Around the stationary com- ponent, the easterly upward momentum flux dominates in the northern winter hemisphere. The waves of zonal wavenumbers 1-3 are dominant. These signals correspond to Rossby waves propagating from mid-latitudes to equatorial regions, because the signal is stronger in higher latitudes of the northern hemisphere. As mentioned above, the horizontal wave momentum flux convergence due to Rossby 
(a)

UW 375-405day FFT sigma $=0.03$

wave number $=1-5$

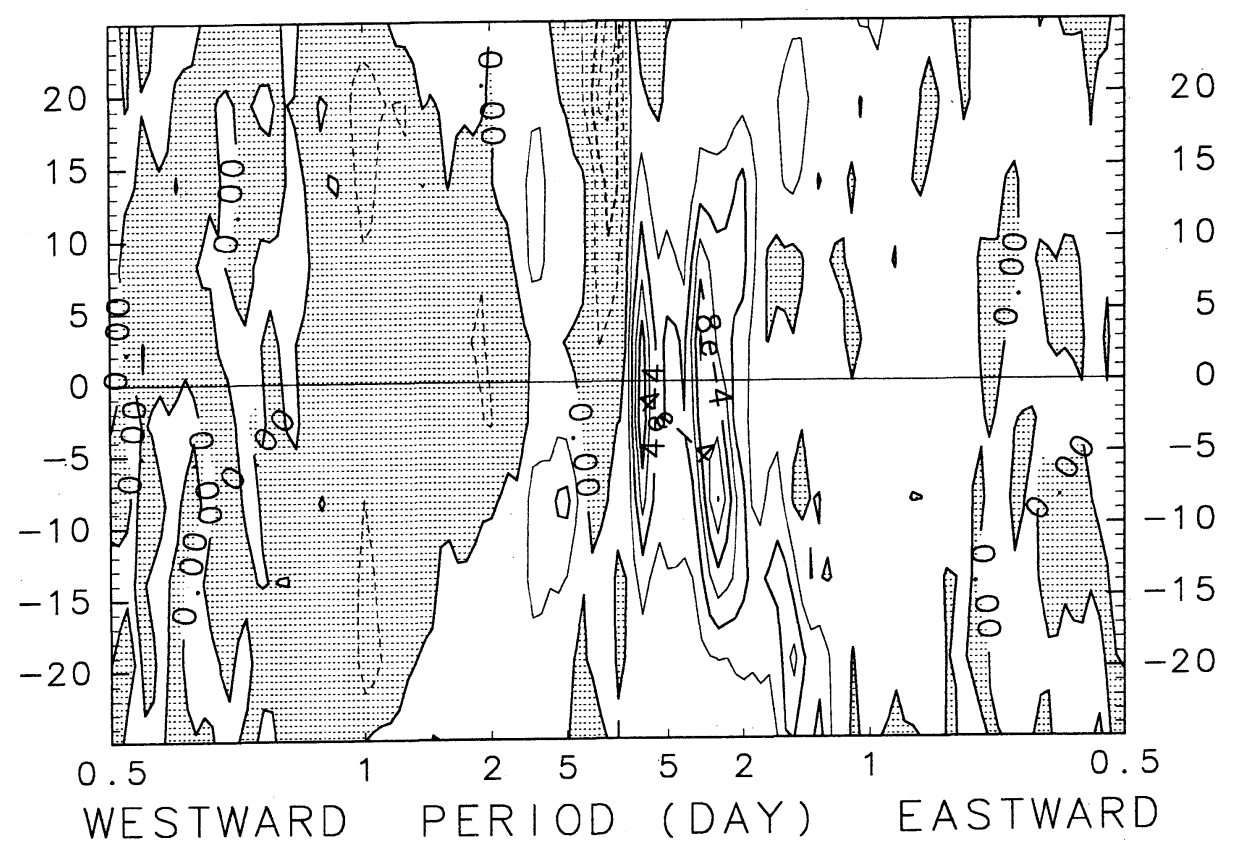

CONTOUR INTERVAL $=2.000 E-04$

(b)

UW $375-405$ day FFT sigma $=0.03$

wave number $=6-10$

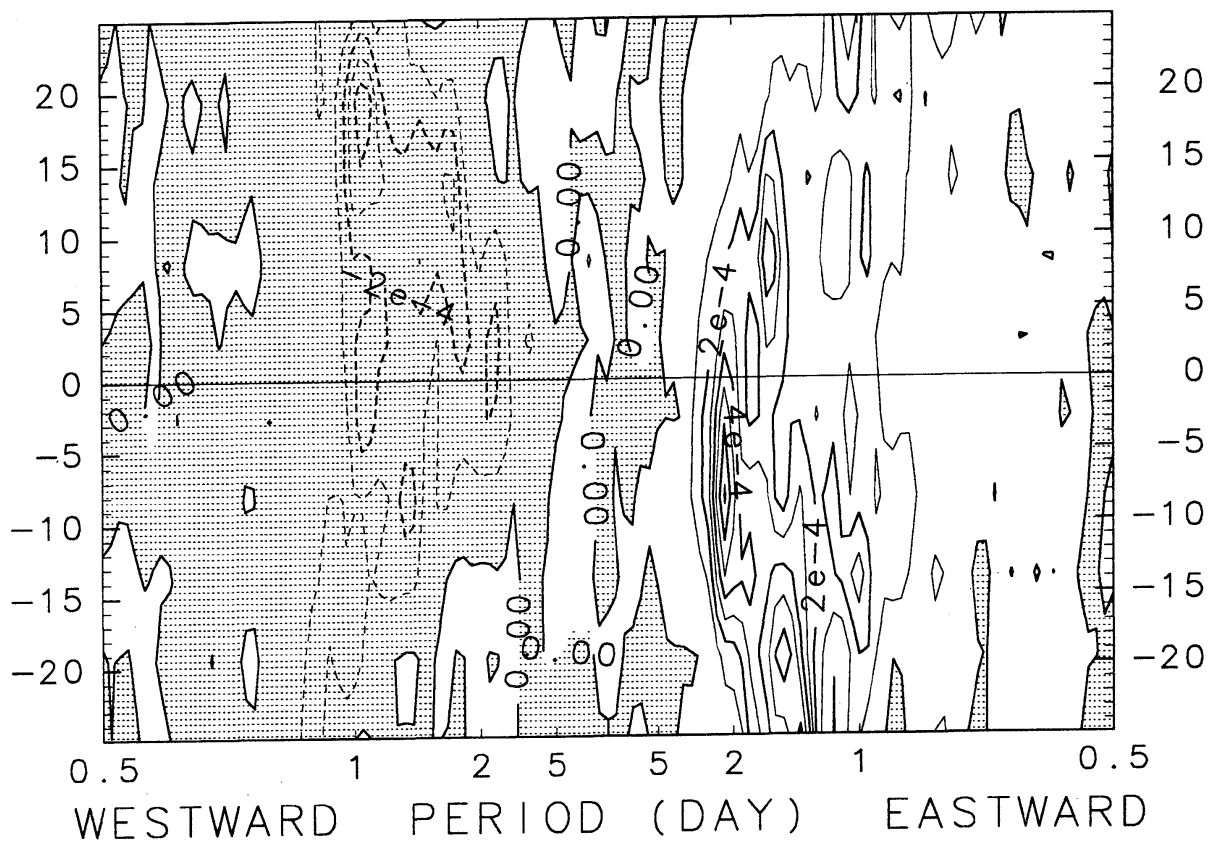

CONTOUR INTERVAL $=1.000 E-04$

Fig. 9. (a) Latitude-period distribution of the power of the wave momentum flux $\overline{u^{\prime} w^{\prime}}$ at sigma level 0.03 (middle stratosphere) from days 375 to 405 . The contour interval is $2.0 \times 10^{-4} \mathrm{~m}^{2} \mathrm{~s}^{-2}$. The zonal wavenumber is from 1 to 5 . The solid lines represent westerly upward momentum flux and the dashed lines easterly upward momentum flux. The shaded regions correspond easterly upward momentum flux. (b) Same as Fig. 9a, except for zonal wavenumbers from 6 to 10. The contour interval is $1.0 \times 10^{-4} \mathrm{~m}^{2} \mathrm{~s}^{-2}$. 
waves contributes to the easterly acceleration of the QBO-like oscillation.

At off-equatorial latitudes there is a signal around 4-5 days in the westward-propagating waves. The vertical wave momentum flux $\overline{u^{\prime} w^{\prime}}$ is positive. The dominant zonal wavenumber is 5 . The signal of the meridional component of the 5-day wave is symmetric about the equator (not shown). This signal, therefore, corresponds to an $n=0$ Rossby-gravity wave. The phase speed of the zonal wavenumber 5 wave is $-20 \mathrm{~ms}^{-1}$, corresponding the YanaiMaruyama wave (Yanai and Maruyama, 1966). However, the vertical EP flux of this wave has a negative value, so the Rossby-gravity wave makes a contribution to the QBO-like oscillation.

There is a signal around 2 days in the westwardpropagating waves at the equator. The dominant zonal wavenumber of this wave signal is 3 . From the meridional structure of the zonal and vertical wind, the wave is an $n=1$ westward-propagating gravity wave. This signal is similar to that of a very strong zonal wavenumber 5 wave of period 2.5 days in the T106S5 model. These short-period 2-3 day wave signals are also seen in the T21L45 model with stronger horizontal diffusion (Fig. 14a of Takahashi and Kumakura (1995)). The signals in Fig. 9a are stronger than those in the previous stronger horizontal diffusion case. These short-period $n=1$ gravity waves make a strong contribution to produce the easterly of the QBO-like oscillation in the model.

There is also a faster westward-propagating wave signal at 1 day. The dominant zonal wavenumber is 1. A zonal wavenumber $s=1$ tidal wave contributes about a third of the wavenumber 1-5 momentum flux around a 1-day period. Other waves of period 1 day have a complicated structure and asymmetry.

Figure $9 \mathrm{~b}$ shows a frequency-latitude section of the vertical wave momentum flux $\overline{u^{\prime} w^{\prime}}$ from zonal wavenumber 6 to 10 at the same level. There are comparable or stronger signals around 1-3 days of westward-propagating waves with a short period. However, the meridional structures of these waves are very complicated and asymmetric. But their combined signal, to some extent, is symmetric about the equator. These waves are like ensembles of westward-propagating $n=1$ equatorial gravity waves and random gravity waves. Note that there is no signal corresponding to a stationary component or Rossby-gravity component from zonal wavenumbers 6 to 10 .

\section{2) Eastward-propagating waves}

There is a strong signal of 10-day period in eastward-propagating waves whose zonal wavenumber is 1. This wave corresponds to the so-called Wallace-Kousky Kelvin wave, though the period is slightly faster than that observed. This wave makes a dominant contribution to the westerly acceleration. There are also strong signals around 2.5 days.
The dominant zonal wavenumber is 4 , and the phase speed is $46 \mathrm{~ms}^{-1}$. It is noted that these waves are somewhat asymmetric about the equator. There are also short-period waves of higher zonal wavenumber with asymmetric structure about the equator. Evidently the waves behave like Kelvin waves and eastward-propagating gravity waves. These Kelvin waves and short-period gravity waves make a significant contribution to the westerly acceleration of the QBO-like oscillation.

\section{Concluding remarks}

The equatorial $\mathrm{QBO}$ in the lower stratosphere has been well simulated in a CCSR/NIES T21L60 general circulation model. The character of the present model is as follows. The vertical resolution is about $500 \mathrm{~m}$ in the upper troposphere and lower stratosphere. We also adopted a smaller fourth-order horizontal diffusion coefficient by one order of magnitude than that used in standard general circulation models. The period of the simulated oscillation is 1.5 years, which is slightly shorter than that observed. The height of the oscillation is slightly higher than that of the real QBO. It seems that mainly the easterly phase is too high. This is related to the general weakness of the easterly phase. The amplitude of the model oscillation is $20 \mathrm{~ms}^{-1}$.

An equatorial-wave analysis has been done. The westerly phase of the simulated QBO-like oscillation is due to Kelvin waves and eastward-propagating gravity waves. This result does not differ from recent observational studies ( $c f$. Maruyama, 1994; Sato et al., 1994). The easterly phase of the oscillation is due to $n=1$ equatorial gravity waves and higher zonal wavenumber $(k=510)$ random gravity waves. The role of the Rossby-gravity wave is smaller in the easterly acceleration of the present model. Further, Rossby waves propagating from the mid-latitude northern winter hemisphere have a role in the easterly acceleration of the simulated QBOlike oscillation.

\section{Acknowledgments}

We would like to thank Dr. A. Numaguti who developed the GCM. We also thank two anonymous reviewers for their careful reading and many helpful comments and suggestions which improved the manuscript. Computations were made on the HITAC S-3800 at the Computer Center of the University of Tokyo. For the graphics, use was made of the GFD-DENNOU library, and GTOOL which was compiled by A. Numaguti. Part of this study was supported by a Grant-in Aid for Scientific Research from the Japanese Ministry of Education, Science and Culture (No. 06452083). 


\section{References}

Boville, B.A., 1991: Sensitivity of simulated climate to model resolution. J. Climate, 4, 469-485.

Dunkerton, T.J., 1983: Laterally-propagating Rossby waves in the easterly acceleration phase of the quasibiennial oscillation. Atmos. -Ocean, 21, 55-68.

Hayashi, Y. and D.G. Golder, 1994: Kelvin and mixed Rossby-gravity waves appearing in the GFDL "SKYHI" general circulation model and the FGGE dataset: Implications for their generation mechanism and role in the QBO. J. Meteor. Soc. Japan, 72, 901935.

Holton, J.R. and R.S. Lindzen, 1972: An updated theory for the quasi-biennial cycle of the tropical stratosphere. J. Atmos. Sci., 29, 1076-1080.

Lindzen, R.S. and C.-Y. Tsay, 1975: Wave structure of the tropical stratosphere over the Marshall Islands area during 1 April-1 July 1958. J. Atmos. Sci., 32, 2008-2021.

McFarlane, N.A., 1987: The effect of orographically excited gravity wave drag on the general circulation of the lower stratosphere and troposphere, J. Atmos. Sci., 44, 1775-1800.

Maruyama, T., 1994: Upward transport of westerly momentum due to disturbances of the equatorial lower stratosphere in the period range about 2 days. A Singapore data analysis for 1983-1993. J. Meteor. Soc. Japan, 72, 423-431.

Nakajima, T., M. Tsukamoto, Y. Tsusima and A. Numaguti, 1995: Modeling of the radiative process in a AGCM. Reports of a new program for creative basic research studies, Studies of global environment change with special reference to Asia and Pacific regions, I-3, 104-123.

Naujokat, B., 1986: An update of the observed quasibiennial oscillation of the stratospheric winds over the tropics, J. Atmos. Sci., 43, 1873-1877.

Numaguti, A., 1993: Dynamics and energy balance of the Hadley circulation and the tropical precipitation zones: Significance of the distribution of evaporation. J. Atmos. Sci., 50, 1874-1887.
Numaguti, A., M. Takahashi, T. Nakajima and A. Sumi, 1995: Development of an atmospheric general circulation model. Reports of a new program for creative basic research studies, Studies of global environment change with special reference to Asia and Pacific regions, I-3, 1-27,

Sato, K, F. Hasegawa and I. Hirota, 1994: Short-period disturbances in the equatorial lower stratosphere. $J$. Meteor. Soc. Japan, 72, 859-872.

Takahashi, M., 1996: Simulation of the stratospheric quasi-biennial oscillation using a general circulation model. Geophys. Res. Letters, 23, 661-664.

Takahashi, M. and J.R. Holton, 1991: The mean zonal flow response to Rossby wave and gravity wave forcing in the equatorial lower stratosphere: Relationship to the QBO. J. Atmos. Sci., 48, 2078-2087.

Takahashi, M. and M. Shiobara, 1995: A note on a QBOlike oscillation in the $1 / 5$ sector three-dimensional model derived from a GCM. J. Meteor. Soc. Japan, 73, 131-137.

Takahashi, M. and T. Kumakura, 1995: Equatorial wave behavior in a three-dimensional sector model: Relation to the simulated QBO-like oscillation and comparison with a T21 general circulation model. J. Meteor. Soc. Japan, 73, 1011-1027.

Takayabu, Y.N., 1994a: Large-scale cloud disturbances associated with equatorial waves. Part I: Spectral features of the cloud disturbances. J. Meteor. Soc. Japan, 72, 433-449.

Takayabu, Y.N., 1994b: Large-scale cloud disturbances associated with equatorial waves. Part II: Westwardpropagating inertio-gravity waves. J. Meteor. Soc. Japan, 72, 451-465.

Wallace, J.W., 1973: General circulation of the tropical lower stratosphere, Rev. Geophys. Space Phys., 11, 191-222.

Wallace, J.W. and V.E. Kousky, 1968: Observational evidence of Kelvin waves in the tropical stratosphere. J. Atmos. Sci., 25, 900-907.

Yanai, M. and T. Maruyama, 1966: Stratospheric wave disturbances propagating over the equatorial Pacific. J. Meteor. Soc. Japan, 44, 291-294. 
準 2 年振動を再現した大循環モデルにおける赤道波について

\author{
高橋正明・趙 南 \\ （東京大学気候システム研究センター） \\ 熊倉俊郎 \\ (長岡技術科学大学 環境情報工学)
}

\footnotetext{
気候システム研究センター／国立環境研究所 $(\mathrm{CCSR} / \mathrm{NIES}) \cdot 大$ 気大循環モデル $(\mathrm{AGCM})$ の第 1 バージ ヨンにおいて準 2 年振動が再現された (Takahashi, 1996)。モデルは、湿潤対流調節のスキームを使ってい る。水平分解能が $\mathrm{T} 21$ で鉛直分解能は約 $500 \mathrm{~m}$ の 60 層モデルである。得られた振動の周期は 1.5 年と少し 早い。

モデル中の赤道波の振舞いを調べてみた。モデルでは、QBO 的振動の西風はKelvin 波と東向きの重力 波が生成している。一方、東風は $n=1$ の西向き重力波、ランダムな西向き重力波や冬の北半球から伝播 してきたRossby 波が作っている。このモデルでは Rossby-重力波は $\mathrm{QBO}$ 的振動の東風生成に少しの役割 を果たしている。
} 